\title{
Development of Chicken Meat Cutlets Incorporating Sesame Seeds
}

\author{
Kanchan Kumari \\ Department of Food Science \& Technology Punjab Agricultural University (PAU) Ludhiana-141004 (Punjab), India
}

\begin{abstract}
The objective of this study was to evaluate the quality of chicken meat cutlets by incorporating functional ingredients sesame seeds at optimized levels. sesame seeds contain many health benefiting compounds such as sesamol (3, 4-methylene-dioxyphenol), sesaminol, furyl-methanthiol, guajacol(2-methoxyphenol),phenyl ethanthiol and furaneol, vinylguacol and furaneol. Sesamol and sesaminol are phenolic anti-oxidants. sesame seeds $(0,1,2,3,4$ and 5 per cent levels) in the products for their optimization in formulation of chicken meat cutlets. On the basis of sensory evaluation, sesame seeds (5 per cent) were incorporated in the chicken meat cutlets and stored under frozen $\left(-20 \pm 2^{\circ} \mathrm{C}\right)$ for two months.. The organoleptic evaluation for the chicken meat cutlets containing 5 per cent sesame seeds was better than control chicken meat cutlets. The chicken meat cutlets containing 5 per cent sesame seeds had higher Appearance, color, texture, flavor and overall acceptability scores than that of the control chicken meat cutlets. It was observed that sesame seeds chicken meat cutlets had significantly $(p \leq 0.05)$ Higher fat, protein, crude fiber, sensory attributes, free fatty acids, ash and lower peroxide value, moisture in comparisons to control samples. The chicken meat cutlets containing sesame seed had significantly $(p \leq 0.05)$ higher acceptability than control chicken meat cutlets. The chicken meat cutlets containing sesame seeds were acceptable up to two months of frozen storage period $\left(-20 \pm 2^{\circ} \mathrm{C}\right)$.
\end{abstract}

Keywords: Chicken meat cutlets, Sesame seeds, quality, organoleptic evaluation

\section{Introduction}

The food processing industry in India is growing at rapid rate of 7.1 percent per annum. Food industry in India is ranked amongst the largest in the country and fifth largest in terms of production, consumption and export. The poultry sector in India has transformed itself from backyard farming to modern industrial scale units, with well organized production, processing and marketing systems. India is fifth largest poultry meat producer in the world producing 2.3 million metric tonnes of poultry meat annually. The country stands fourth globally in layer and sixth in broiler population.

The population of broilers has been rising at a rate of 8 to 10 percent per annum. The country produces about 450 million broilers annually. The average per capita poultry meat consumption has increased from 0.69 kilograms to 1.9 kilograms between 2000 to 2007 (Yadav 2009)

Lipid oxidation and auto-oxidation are major causes of deterioration and reduced shelf life of meat products. Oxidation of lipids has detrimental effects on color, flavor, texture and nutritive value of meat (Anon 1991). Antioxidants can minimize or prevent lipid oxidation in food products. Antioxidants are important not only for food protection but also for the defense of living cells against oxidative damage. Synthetic anti-oxidants like BHT and BHA have been successfully used to prevent the oxidation in meat products. However, the synthetic anti-oxidants used currently have been found to exhibit various health hazards (Shahidi, Janita \& Wanasundara, 1992). Reports of adverse health effects of these synthetic chemicals have lead to growing interest in natural sources of anti-oxidants in meat products. In addition there has been growing interests in natural anti-oxidants because of their safety, consumer acceptability and greater application in extending the shelf life of foods.
Sesame seeds are widely considered healthful foods. They are high in energy but contain many health benefiting nutrients, minerals, antioxidants and vitamins that are essential for wellness. The seeds are especially rich in monounsaturated fatty acid oleic acid, which comprise up to 50\% fatty acids in them. Oleic acid helps to lower LDL or "bad cholesterol" and increase HDL or "good cholesterol" in the blood. Research studies suggest that Mediterranean diet which is rich in mono-unsaturated fats help to prevent coronary artery disease and stroke by favoring healthy lipid profile. The seeds are also very good source of dietary proteins with fine quality amino acids that are essential for growth, especially in children. Just $100 \mathrm{~g}$ of seeds provide about $18 \mathrm{~g}$ of protein (32\% of daily-recommended values).

In addition, sesame seeds contain many health benefiting compounds such as sesamol (3, 4-methylene-dioxyphenol), sesaminol, furyl-methanthiol, guajacol (2-methoxyphenol), phenylethanthiol and furaneol, vinylguacol and decadienal. Sesamol and sesaminol are phenolic anti-oxidants. Together, these compounds help stave off harmful free radicals from the body.Sesame is amongst the seeds rich in quality vitamins and minerals. They are very good sources of B-complex vitamins such as niacin, folic acid, thiamin (vitamin B1), pyridoxine (vitamin B6), and riboflavin.100 g of sesame contains $\mathbf{9 7}$ mcg of folic acid, about $25 \%$ of recommended daily intake. Folic acid is essential for DNA synthesis. When given in expectant mothers during periconception period, it may prevent neural tube defects in the baby. Niacin is another B-complex vitamin found abundantly in sesame. About $4.5 \mathrm{mg}$ or $28 \%$ of dailyrequired levels of niacin is provided by just $100 \mathrm{~g}$ of seeds. Niacin help reduce LDL-cholesterol levels in the blood.

The seeds are incredibly rich sources of many essential minerals. Calcium, iron, manganese, zinc, magnesium, selenium, and copper are especially concentrated in sesame seeds. Many of these minerals have vital role in bone mineralization, red blood cell production, enzyme synthesis, 


\section{International Journal of Science and Research (IJSR) \\ ISSN (Online): 2319-7064 \\ Index Copernicus Value (2013): 6.14 | Impact Factor (2014): 5.611}

hormone production, as well as regulation of cardiac and skeletal muscle activities.Just a hand full of sesame a day provides enough recommended levels of phenolic antioxidants, minerals, vitamins and protein. (www.nutritionand-you.com)

So the present investigation was undertaken to develop chicken meat cutlets containing sesame seeds and to study physico - chemical, organoleptic analysis of the prepared product.

\section{Materials and Methods}

\section{1) Raw materials}

\subsection{Chicken meat}

Frozen minced chicken meat of Republic of Chicken brand (400gms unit), was purchased from their outlet in Ludhiana and stored at $-20 \pm 2{ }^{\circ} \mathrm{C}$ in deep freezer, till its use in the preparation of chicken meat cutlets. The chicken meat was thawed using microwave oven (Batliboi Eddy Co. Model No. ER-5054 D) for 2 minutes at power level 4.

\subsection{Sesame seeds}

Sesame seeds was procured from the local market and roasted under low flame for 2 minutes. After roasting they are incorporated into the batter for the preparation of chicken meat cutlets.

\subsection{Spice mix and Additives}

A pre-standardized formulation of dry spices was prepared. Cinnamon, coriander, cumin powders of MDH brand and black pepper and red pepper of Catch brand were procured from the local Ludhiana market for the preparation of dry spice mix.

\subsection{Green Curry Stuff (GCS)}

For the preparation of Green Curry Stuff Onion, Peas, Coriander, Potatoes were purchased from the local market. Ginger and Garlic paste of Smith and Jones brand was also obtained from local market. Onions were washed, peeled and paste was prepared using food processor ( Kenstar Karishma Multi Processor, Model no. MF0808). Green Curry Stuff (GCS) was prepared by blending onion paste, garlic paste and ginger paste (2:1:1 respectively).

Peas were taken out from pods and coarsely grinded using pestle and mortar for their incorporation in the cutlets. Coriander leaves were manually cut into pieces with the help of knife. Potatoes were washed, boiled and mashed manually for their incorporation into chicken meat cutlets.

Food grade sodium alginate, calcium carbonate, sodium nitrite, sodium nitrate was procured from the local market. Refined Groundnut oil (Fortune) and Iodized salt (Tata) were used in the formulation.

\section{2) Standardization of product formulation}

The recipe of chicken meat cutlets was standardized by consulting literature and by taking the opinion of taste panel members during product standardization. Trials were conducted using different levels of salt and spices for the standardization of the recipe. After standardizing of the recipe, the trials were conducted incorporating sesame seeds at $0,2,4,5,6,8$ and 10 per cent levels, On the basis of sensory evaluation, best levels of sesame seeds 5 per cent was selected for incorporation in final products i.e. chicken meat cutlets.

\section{3) Preparation of cutlets}

The chicken meat mince, salt and sodium nitrite were mixed in Hobart mixer Model N-50 for five minutes. Sesame seeds (5.0 per cent) were added followed by dry spices mix and other additives as per the formulation to form uniform batter. After uniform mixing of all the ingredients, the batter was moulded into cutlets with the help of oval shaped metallic moulds $10 \mathrm{~cm}$ long and $6.5 \mathrm{~cm}$ maximum width. The cutlets (approximately $80 \mathrm{gm}$ each ) were precooked in hot air oven at $200^{\circ} \mathrm{C}$ for 12 minutes. The precooked cutlets were removed from the moulds and packed.

\section{4) Physico-chemical analysis}

The proximate composition parameters of moisture, protein, fat, crude fiber, Peroxide value and Free fatty acid value were carried out both for control and product chicken meat cutlets.

\section{5) Organoleptic evaluation}

The products were organoleptically evaluated on the day of preparation. A ten member semi-trained sensory panel was selected from the faculty members of PAU and PG students. Nine-point Hedonic scale was used for evaluation of cutlets for appearance, color, flavor, texture, juiciness and overall acceptability (Larmond 1970).

\section{6) Storage Studies}

Chicken meat cutlets were prepared and packed in different packaging materials namely conventional and vacuum packaging (HDPE) for chicken meat cutlets. Chicken meat cutlets were frozen stored $\left(-20 \pm 2^{\circ} \mathrm{C}\right)$ for estimation by conducting tests for changes in moisture content, protein content, free fatty acid content, peroxide value and overall acceptability at regular intervals of 15 days interval over a period of two months for chicken meat cutlets.

\section{Results and Discussions}

\section{Proximate composition of minced chicken meat and sesame seeds}

Data embodied in Table 1 represents the proximate composition of raw materials like chicken meat and sesame seeds used in the preparation of chicken meat cutlets.

Table 1: Proximate Composition of raw materials $(\mathrm{n}=3)$

\begin{tabular}{|c|c|c|c|c|c|}
\hline $\begin{array}{c}\text { Raw } \\
\text { materials }\end{array}$ & $\begin{array}{c}\text { Moisture } \\
(\%)\end{array}$ & Protein (\%) & Fat (\%) & $\begin{array}{c}\text { Ash } \\
(\%)\end{array}$ & Fibre (\%) \\
\hline Chicken & $72.24 \pm 0.01$ & $18.92 \pm 0.01$ & $\begin{array}{c}6.41 \pm \\
0.04\end{array}$ & $\begin{array}{c}1.22 \pm \\
0.02\end{array}$ & $0.17 \pm 0.05$ \\
\hline $\begin{array}{c}\text { Sesame } \\
\text { seeds }\end{array}$ & $3.82 \pm 0.01$ & & $\begin{array}{c}48.47 \pm \\
0.08\end{array}$ & $\begin{array}{c}3.41 \pm \\
0.04\end{array}$ & $3.23 \pm 0.09$ \\
\hline
\end{tabular}

Appearance, color, texture, flavor and overall acceptability scores were maximum at 5.0 per cent level of sesame seed incorporation. So this level was selected and also beyond that there was perceptible change in flavor and its color darkened. 


\section{International Journal of Science and Research (IJSR) \\ ISSN (Online): 2319-7064 \\ Index Copernicus Value (2013): 6.14 | Impact Factor (2014): 5.611}

Table 2: Effect of sesame seeds incorporation levels on the sensory quality of chicken meat cutlets. (n=9)

\begin{tabular}{|c|c|c|c|c|c|}
\hline Level of sesame seeds (\%) & Appearance & Color & Texture & Flavor & Overall acceptability \\
\hline 0 & $6.93 \pm 0.1$ & $6.54 \pm 0.1$ & $7.03 \pm 0.1$ & $6.74 \pm 0.1$ & 6.81 \\
\hline 2 & $7.11 \pm 0.1$ & $6.91 \pm 0.1$ & $7.33 \pm 0.1$ & $7.20 \pm 0.2$ & 7.14 \\
\hline 4 & $7.61 \pm 0.1$ & $7.34 \pm 0.2$ & $7.87 \pm 0.2$ & $7.48 \pm 0.1$ & 7.57 \\
\hline 5 & $8.12 \pm 0.1$ & $7.93 \pm 0.2$ & $8.31 \pm 0.1$ & $8.51 \pm 0.1$ & 7.25 \\
\hline 6 & $7.44 \pm 0.2$ & $7.63 \pm 0.1$ & $7.22 \pm 0.2$ & $7.81 \pm 0.2$ & 7.39 \\
\hline 8 & $7.22 \pm 0.1$ & $7.31 \pm 0.2$ & $7.31 \pm 0.1$ & $7.61 \pm 0.1$ & 6.75 \\
\hline 10 & $7.02 \pm 0.1$ & $7.23 \pm 0.1$ & $6.82 \pm 0.2$ & $6.21 \pm 0.2$ & 0.21 \\
\hline C.D. $(\mathrm{p} \leq 0.05)$ & 0.31 & 0.41 & 0.14 & 0.34 & \\
\hline
\end{tabular}

Moisture content of the control chicken meat cutlets was higher than that of chicken meat cutlets containing 5 per cent sesame seeds. This may be due to the low moisture content of the sesame seed. Protein, fat, ash and fibre content of the control chicken meat cutlets was higher than that of chicken meat cutlets containing 5 per cent sesame seeds, this may be due to the higher protein ,fat, ash and fibre content of the sesame seeds in compare to chicken mince.

Free fatty acids are the products of enzymatic or microbial degradation of lipids. Determination of FFA gives information about stability of fat during storage. the average free fatty acid value of control was lower than than that of chicken meat cutlets containing 5 per cent sesame seeds. The seeds are especially rich in mono-unsaturated fatty acid oleic acid, which comprise up to $50 \%$ fatty acids in them. Oleic acid helps to lower LDL or "bad cholesterol" and increase HDL or "good cholesterol" in the blood.
The primary products of lipid oxidation are hydroperoxides, therefore it seemed reasonable to determine the concentration of peroxides in the meat samples to study the extent of oxidation. Peroxide values were used as indices to assess the level of lipid oxidation in cooked chicken meat cutlets during frozen storage $\left(-18 \pm 2^{0} \mathrm{C}\right)$. the average peroxide value value of control was higher than than that of chicken meat cutlets containing 5 per cent sesame seeds. The addition of sesame seed in chicken meat cutlets appears to decrease the lipid per oxidation as measured by decrease in peroxide value, probably because of their presence of Sesamol and sesaminol as phenolic anti-oxidants by terminating free radical chain reaction.

The organoleptic evaluation for the chicken meat cutlets containing 5 per cent sesame seeds was better than control chicken meat cutlets. The chicken meat cutlets containing 5 per cent sesame seeds had higher Appearance, color, texture, flavor and overall acceptability scores than that of the control chicken meat cutlets.

Table 4: Proximate composition parameter of both cooked chicken meat cutlets and that containing 5 per cent sesame seeds

\begin{tabular}{|c|c|c|c|c|c|c|c|}
\hline Chicken Cutlets & Moisture & Protein & Fat & Ash & Crude fiber & Free fatty acids & Peroxide value \\
\hline Control & $62.28 \pm 0.12$ & $16.48 \pm 0.03$ & $10.43 \pm 0.05$ & $2.24 \pm 0.03$ & $1.49 \pm 0.02$ & $0.11 \pm 0.02$ & $0.03 \pm 0.01$ \\
\hline Containing sesame Seeds & $59.86 \pm 0.09$ & $17.64 \pm 0.02$ & $11.78 \pm 0.04$ & $3.01 \pm 0.04$ & $3.23 \pm 0.07$ & $0.17 \pm 0.03$ & $0.00 \pm 0.00$ \\
\hline
\end{tabular}

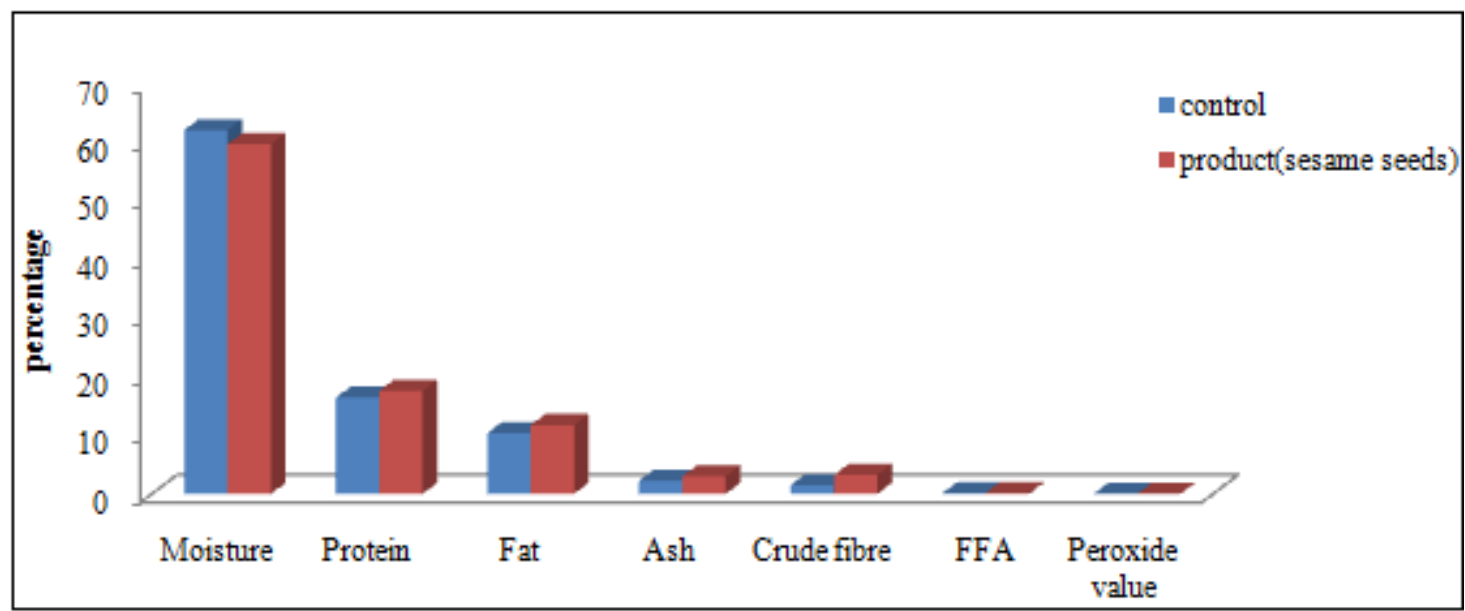

Figure 1: Proximate composition parameter of both control and product containing sesame seeds

\section{Conclusion}

It was concluded that good quality chicken meat cutlets can be produced by incorporating natural plant antioxidant sesame seed at 5 per cent level. It increased the nutritional value by increasing protein, ash and fiber content. The seeds are especially rich in mono-unsaturated fatty acid oleic acid, which comprise up to 50 per cent fatty acids in them. Oleic acid helps to lower LDL or "bad cholesterol" and increase
HDL or "good cholesterol" in the blood. It enhanced the physical quality of the formulated cutlets by increasing the water holding capacity, and decreasing the cooking loss. Sesame seeds incorporating chicken meat cutlets had proved healthier food for consumer without detrimental effect on the sensory attributes of the Product. 


\section{References}

[1] Anon (1991) Natural antioxidants capitalize on "clean label" trend. Prepared Foods 160: 83.

[2] Besbes S, Attia H, Deroanne C, Makni S and Blecker C (2008) Partial replacement of meat by pea fiber and wheat fiber: Effect on the chemical composition, cooking characteristics and sensory properties of beef burgers. J Fd Quality 31: 480-89.

[3] Chang H C and Carpenter J A (1997) Optimizing quality of frankfurters containing oat bran and added water.J Fd Sci 62: 194-97, 202.

[4] Fernandez-Lopez J, Fernandez-Gines, J M, AlesonCarbonell L, Sendra E, Sayas-Barbera E and PerezAlvarez J A (2004) Application of functional citrus by products to meat products. Trends in Food Science and Technology. 15:176-85.

[5] Larmand E (1970) Method of sensory evaluation of food. Canadian Department of Agriculture Publishers 1284.

[6] Shahidi, F., Janita, P. K., \& Wanasundara, P. D. (1992).Phenolic antioxidants. Critical Reviews in Food Science and Nutrition, 32, 67-103.

[7] Yadav M P (2009) Incorporation of draught resistance genes in poultry feed crops necessary. The Hindu Survey Indian Agri 3:13-16.

[8] www.nutrition-and-you.com) 